Association of COVID-19 Misinformation with Face Mask Wearing and Social Distancing in a Nationally Representative US Sample

Robert Hornik $^{\mathrm{a} * *}$, Ava Kikut ${ }^{\mathrm{a}^{*}}$, Emma Jesch $^{\mathrm{a}^{*}}$, Chioma Woko ${ }^{\mathrm{a}^{*}}$, Leeann

Siege $^{\mathrm{a}^{*}}$, and Kwanho Kim ${ }^{\mathrm{a}^{*}}$

${ }^{a}$ Annenberg School for Communication, University of Pennsylvania, Philadelphia, PA, USA

*These authors contributed equally to this work.

**Corresponding author email: robert.hornik@asc.upenn.edu

This is a working paper and has not yet been subject to peer review.

Word count: 4408

Date: August 18, 2020 


\title{
Association of COVID-19 Misinformation with Face Mask Wearing and Social Distancing in a Nationally Representative US Sample
}

\author{
Wide-spread misinformation about the COVID-19 pandemic has presented challenges \\ for communicating public health recommendations. Should campaigns to promote \\ protective behaviors focus on debunking misinformation or targeting behavior-specific \\ beliefs? To address this question, we examine whether belief in COVID-19 \\ misinformation is directly associated with two behaviors (face mask wearing and social \\ distancing), and whether behavior-specific beliefs can account for this association and \\ better predict behavior, consistent with behavior-change theory. We conducted a \\ nationally representative two-wave survey of U.S. adults from 5/26/20-6/12/20 \\ $(n=1074)$ and $7 / 15 / 20-7 / 21 / / 20(n=889$; follow up response $83 \%)$. Scales were \\ developed and validated for COVID-19 related misinformation beliefs, social \\ distancing and face mask wearing, and beliefs about the consequences of both \\ behaviors. Cross-lagged panel linear regression models assessed relationships among \\ the variables. While belief in misinformation was negatively associated with both face \\ mask wearing $(\mathrm{B}=-.27, \mathrm{SE}=.06)$ and social distancing behaviors $(\mathrm{B}=-.46, \mathrm{SE}=.08)$ \\ measured at the same time, misinformation did not predict concurrent or lagged \\ behavior when the behavior-specific beliefs were incorporated in the models. Beliefs \\ about behavioral outcomes accounted for face mask wearing and social distancing, both \\ cross-sectionally $(\mathrm{B}=.43, \mathrm{SE}=.05 ; \mathrm{B}=.63, \mathrm{SE}=.09)$ and lagged over time $(\mathrm{B}=.20$, \\ $\mathrm{SE}=04 ; \mathrm{B}=.30, \mathrm{SE}=.08$ ). In conclusion, belief in COVID-19-related misinformation is \\ less relevant to protective behaviors, but beliefs about the consequences of these \\ behaviors are important predictors. With regard to misinformation, we recommend \\ health campaigns aimed at promoting protective behaviors emphasize the benefits of \\ these behaviors, rather than debunking unrelated false claims.
}

Keywords: COVID-19; misinformation; face mask wearing and social distancing

\section{Introduction}

Throughout the coronavirus pandemic (COVID-19), false and misleading information - or "misinformation" - about the disease has proliferated across both mainstream and social media (Depoux et al., 2020; Kouzy et al., 2020; Mian \& Khan, 2020). These rumors include myths about the origins of the virus (e.g. the virus was man-made), unfounded claims about 
the severity of the virus (e.g. the virus is less deadly than the seasonal flu), and false statements about the existence of a vaccine or cure (e.g. the malaria drug Hydroxychloroquine is an effective treatment) (Brennen et al., 2020; Sharma et al., 2020). An important health communication question is whether belief in misinformation decreases engagement in protective health behaviors. If so, it may be worthwhile to identify effective communication approaches to help combat misinformation. If not, communication strategies might instead focus on targeting other beliefs, particularly those that are proven to be associated with protective health behaviors.

In the current two-wave survey study involving a nationally representative sample, we assess the relationship between belief in COVID-19 misinformation and two CDCrecommended protective behaviors: social distancing and wearing face masks (Centers for Disease Control, 2020). In addition, we consider the role of specific beliefs about the consequences of these behaviors (i.e. behavior-specific outcomes and norms). Ultimately, we ask whether there is a need for corrective communication efforts to address COVID-19 misinformation, or if addressing beliefs directly linked to protective behaviors is a more promising health campaign strategy.

\section{Past Studies}

Concern about misinformation predates the COVID-19 pandemic. Much attention has been paid to the proliferation of political misinformation, particularly in the wake of the 2016 U.S. presidential election (Guess et al., 2018), and how to effectively counter it (Cook et al., 2015). Misinformation is comparatively understudied in the health domain (Kreps \& Kriner, 2020; Southwell et al., 2019). There is some evidence that belief in specific false health information is associated with undesirable outcomes, including lowered vaccination rates (Jolley \& Douglas, 2014; Oliver \& Wood, 2014), reduced contraceptive use (Thorburn \& 
Bogart, 2005), and nonadherence to antiretroviral treatment (Bogart et al., 2010), although overall, the research is limited and the findings mixed (Nan et al., in press).

Emerging research on the behavioral effects of COVID-19 misinformation is similarly inconsistent. To date, many of the available studies are still in preprint form. All focus on the relationship between false beliefs and behaviors (or intentions to undertake behaviors). While some studies find associations between belief in COVID-19 misinformation and reduced self-protective behaviors (Allington et al., 2020; Banai et al., 2020; Bertin et al., 2020; Bierwiaczonek et al., 2020; Erceg et al., 2020; Sternisko et al., 2020; Swami \& Barron, 2020; Teovanovic et al., 2020), others find no evidence of associations (Alper et al., 2020; Díaz \& Cova, 2020). Still others find associations for some behaviors but not others (Imhoff \& Lamberty, 2020; Pummerer \& Sassenberg, 2020). These inconsistent results may be driven by the varying quality, size, and representativeness of samples, by the validity of measures employed, or by the variety of assessed self-protective behaviors, ranging from social distancing and containment, to hygiene and hoarding tendencies, to future intentions to vaccinate. Inconsistency may also be driven by varying depth and breadth of assessed misinformation, false beliefs, rumors, and conspiracy theories. Some studies focused on just a few false beliefs (e.g. "Coronavirus was developed and spread around the world by certain people for their own purposes"; Alper et al., 2020; Sternisko et al., 2020) whereas others developed multi-item misinformation scales, assessing a broader span of beliefs, ranging from possible treatments ("Colloidal silver is a potentially good cure for this coronavirus strain"; Erceg et al., 2020) to origins ("5G electromagnetic field exposure played a role in the coronavirus pandemic"; Teovanovic et al., 2020).

These early studies provide some evidence that beliefs in certain kinds of COVID-19 misinformation are associated with self-protective behaviors. However, none of these studies systematically assess misinformation-behavior associations while taking into account 
potential associations between the behaviors and their related beliefs. The current study will add to that evidence base, featuring research that relies on a large, nationally representative longitudinal survey and uses validated measures directly assessing major constructs. This study evaluates whether belief in misinformation remains associated with protective behaviors when adjusting for beliefs about the consequences of these behaviors.

An observed negative association of belief in misinformation and protective behaviors would not establish that false belief correction will influence behaviors or merits priority attention in a communication campaign. COVID-19 misinformation often does not, on its face, directly relate to the protective behaviors. For example, rumors about the origins of the viral outbreak are not explicitly linked to consequences of face mask wearing or social distancing. Major theories of behavior prediction, including the reasoned actioned approach, hypothesize that behavior is influenced by behavior-specific beliefs, such as anticipated outcomes of the behavior (behavioral beliefs), whether significant others would approve of the behavior (normative beliefs), and perceived ability to perform the behavior (control beliefs) (Fishbein et al., 2001; Fishbein \& Ajzen, 2015). Based on these theories, misinformation unrelated to specific behaviors would not directly influence behavior. Instead, beliefs about the consequences of the behaviors would account for, or mediate, any association of misinformation and behavior.

\section{The Present Study}

We conducted a nationally representative two-wave survey of 1074 adults living in the United States first interviewed between May 26-June 12, 2020 (T1) and then again between July 15-21, 2020 (T2). The follow up response rate was quite high: 83\%. Respondents at both waves reported their level of agreement with highly proliferated unfounded rumors about COVID-19, the frequency with which they engaged in activities which were inconsistent with strict social distancing and stay-at-home recommendations, and how often 
they wore a face mask or other covering while engaging in activities for which face masks are recommended. We also measured and created parallel scales for beliefs about the perceived consequences of both social distancing and face mask wearing. Drawing from the reasoned actioned approach, we asked about specific outcomes and norms relevant to each behavior (Fishbein \& Ajzen, 2015).

Adjusting for causally prior potential confounders, we first measured the crosssectional associations between overall endorsement of false statements and each protective behavior, and then addressed whether the observed associations were accounted for by the measured beliefs about the consequences of those behaviors. We predicted a priori that the role of misinformation would be minimized in the presence of these related behavioral beliefs (https://aspredicted.org/blind.php? $\mathrm{x}=\mathrm{g} 2 \mathrm{eq} 8 \mathrm{w}$ ). Longitudinal analyses were employed to strengthen claims of influence; we measured the association between T1 beliefs and T2 behavior, adjusting for T1 behavior and all measured confounders. Finally, to test for reciprocal influence, we conducted a parallel analysis to see whether T1 behavior predicted T2 belief, adjusting for T1 belief and confounders.

\section{Methods}

\section{Participants}

A nationally representative sample of 1,074 adult U.S. residents were recruited from Social Science Research Solutions (SSRS)'s Opinion Panel (Social Science Research Solutions $(S S R S)$, n.d.) and completed surveys online or by phone (cell phone and landline) in English or Spanish. In the first wave (T1), the cooperation rate for the survey was 54\% (recruitment rate with the underlying panel varies from $2-4 \%$ depending on the mode of recruitment). The sample included residents from each U.S. state and survey weights developed by SSRS were used to ensure that participants matched the U.S. population on key demographic variables. 
Characteristics of original T1 survey participants are summarized in Table 4. The follow-up round (T2), on average undertaken six weeks later, successfully re-recruited 889 of these respondents $(83 \%)$.

\section{Measures}

Participants were asked a series of questions about their COVID-19-related beliefs and behaviors, as well as other personal characteristics. We constructed multi-item scales representing belief in misinformation, engagement in social distancing, face mask wearing, beliefs about the benefits of social distancing, and beliefs about the benefits of face mask wearing. Scales were used to represent each of these variables to capture the richness of each concept of interest and avoid potential bias or measurement error that could be caused by reliance on single-item measures. We assessed the internal consistency of the items composing each scale using Cronbach's alpha; used principal components analysis (PCA) to test whether all items would load onto a single factor; and, where possible, measured the correlation between the summed scale and another measure of the same construct. The complete survey instrument used in this study can be requested from the authors.

\section{Face mask wearing scale}

To measure participants' use of face masks, respondents were asked whether they had engaged in specific activities over the past week (presented in random order), and if they had, the frequency with which they had worn a face mask while engaging in those activities. The language of the questions can be found in Table 1. There was high consistency across items $(\mathrm{T} 1$ and $\mathrm{T} 2$ alphas $=.88 ; .93)$ with all items loading on a single dimension in PCA. Respondents were separately asked "When you went outside your home in the past 7 days, how often did you wear a mask or other face covering?" Responses to this question were 
highly correlated with the scale $(\mathrm{T} 1$ and $\mathrm{T} 2: \mathrm{r}=.73 ; .61)$, providing further evidence for the validity of the scale.

\section{Social distancing scale}

To measure the extent to which participants had followed social distancing recommendations over the past week, respondents were asked whether they had engaged in several activities (presented in random order), six of which would necessarily involve violating social distancing recommendations. These six items were measured dichotomously as yes / no and responses were summed to create a scale. Respondents were moderately consistent across the six activities (T1 and T2 alphas $=.65$ and .68$)$; both loaded on single dimensions in the PCA. The full language of the questions is presented in Table 2. In a separate question, respondents were asked "Social distancing is staying at least 6 feet away from other people in public places. In the past 7 days, how often have you practiced social distancing?" The correlations between responses to this question and the summed scale were .57 (T1) and .55 (T2), providing further evidence for scale validity.

\section{Misinformation belief scale}

A set of ten items was used to measure the extent to which participants agreed with misinformation about COVID-19. We compiled misinformation from a variety of sources, including fact-checking organizations (WHO Myth Busters), databases (Poytner's International Fact-Checking Network; Wikipedia's page on "Misinformation Related to the COVID-19 Pandemic"), and articles (Brennen et al., 2020; Erceg et al., 2020; Pennycook et al., 2020; Sharma et al., 2020). We focused on eight misinformation items while developing our scale due to their prominence in the media (Brennen et al., 2020) and because they formed a single dimension in the PCA. Items were presented in random order and measured on a 4-point scale $(1=$ strongly disagree, $4=$ strongly agree, with a 'not sure' alternative 
scored at the midpoint of the scale). Respondents were consistent in their tendency to agree or disagree with false beliefs (both $\mathrm{T} 1$ and $\mathrm{T} 2$ alphas $=.84$ ). The language of the questions and the (weighted T1 and T2) proportion of respondents who answered each question are presented in Table 3.

Face mask / social distance behavior-specific belief scales

Participants were asked to agree or disagree with parallel batteries of six items about the behavioral outcomes (five items each) and norms (one item each) of social distancing or wearing face masks (Fishbein \& Ajzen, 2015): "How much do you (disagree) or (agree) that if you [maintain social distance] / [wear a mask or other face covering in public places] every day for the next two weeks: you will protect more vulnerable people in our society, you will help the healthcare system so that people who need urgent medical care will receive it, you will slow the spread of the coronavirus, it will prevent you from transmitting coronavirus to others, your family and friends will approve of your decision, you will be less likely to get sick." Respondents were randomly asked the face mask or social distancing battery first, and the six items within each battery were presented in random order. Responses within each scale were highly consistent (T1 and T2 face mask alphas $=.93$ and .94 ; social distance alphas $=.92$ and .93 ) and consistently formed single dimensions on the PCA. Respondents who reported high favorable belief scores for face mask wearing also reported high scores for beliefs about social distancing (both $\mathrm{T} 1$ and $\mathrm{T} 2 \mathrm{r}=.90$ ).

\section{Analyses}

We report distributions of responses on each item and scale, bivariate correlations between beliefs in misinformation, wearing face masks, social distancing, and beliefs about the consequences of wearing face masks and social distancing as well as a set of potential 
confounders (Table 4). We conducted a series of linear regression analyses using MPlus 8.3. Samples were weighted to represent the US population; the parameters were estimated with maximum likelihood with robust standard errors (MLR). Missing values were handled using the full information maximum likelihood (FIML) method.

We first fit a series of cross-sectional models to test whether belief in misinformation was significantly associated with face mask wearing and social distancing scales, and whether these relationships remained significant when controlling for potential confounders. Next, we assessed whether the relationships between belief in misinformation and wearing face masks or social distancing remained when adjusting for beliefs about the positive consequences of those behaviors. We then conducted longitudinal analyses, fitting crosslagged panel correlation models predicting behaviors and beliefs at $\mathrm{T} 2$ from $\mathrm{T} 1$ measures of those variables. To allow for measurement of over-time change, the final analyses include only the $83 \%$ of respondents who provided information for T1 and T2 $(n=889)$.

\section{Results}

\section{Descriptive Data}

Face mask wearing is inconsistently performed and is contingent on the activity (Table 1). At T1, between $38 \%$ and $89 \%$ of respondents reported engaging in each activity, and there was variation in face mask wearing frequency, depending on the behavior. For example, at T1 $14 \%$ of respondents wore masks every time they went out for fresh air or for exercise, compared to $69 \%$ who always wore masks while shopping for groceries or other necessities. Over the six-week period between waves, respondents retained for both waves reported increases in face mask wearing, particularly for grocery shopping $(+14 \%)$ and for meeting with people outside $(+10 \%)$. 
Table 1: Past-week compliance with face mask wearing while engaging in activities for which face masks are recommended $(\%$ who did each activity, and $\%$ of those who wore face masks every time, T1 and T2) $n=889$, weighted data.

\begin{tabular}{|c|c|c|c|c|c|}
\hline \multirow[b]{2}{*}{$\begin{array}{l}\text { How often did you wear a mask or } \\
\text { other face covering in the past } 7 \\
\text { days when you were doing each of } \\
\text { the following activities never, } \\
\text { some of the time, most of the time, } \\
\text { every time: }\end{array}$} & \multicolumn{2}{|c|}{$\mathrm{T} 1(\%)$} & \multicolumn{2}{|c|}{$\mathrm{T} 2(\%)$} & \multirow[t]{2}{*}{$\begin{array}{l}\text { Change } \\
(\%)\end{array}$} \\
\hline & did activity & $\begin{array}{l}\text { wore mask } \\
\text { every time }\end{array}$ & did activity & $\begin{array}{l}\text { wore mask } \\
\text { every time }\end{array}$ & \\
\hline $\begin{array}{l}\text { Getting fresh air or exercising } \\
\text { outdoors }\end{array}$ & 89.1 & 14 & 86.9 & 14.7 & 0.7 \\
\hline $\begin{array}{l}\text { Shopping for groceries or other } \\
\text { necessities }\end{array}$ & 88.4 & 69.1 & 91.5 & 82.8 & 13.7 \\
\hline Walking a dog or other pet & 46.0 & 11.5 & 42.5 & 14.3 & 2.8 \\
\hline Meeting people socially outside & 69.5 & 26.4 & 70.0 & 36.1 & 9.7 \\
\hline Taking a child outside to play & 38.0 & 18.1 & 33.6 & 22.4 & 4.3 \\
\hline Meeting people socially indoors & 66.2 & 23.9 & 65.0 & 28.3 & 5.0 \\
\hline Working at a job outside your home & 48.9 & 42.2 & 48.3 & 53.1 & 8.9 \\
\hline
\end{tabular}

Between $30 \%$ and $74 \%$ reported specific behaviors consistent with social distancing at T1, with the lowest level of compliance reflecting entertaining others in one's own home (Table 2). While face mask wearing increased over the six weeks between waves, respondents reported less social distancing, including less staying away from restaurants ($6 \%)$ and less remaining at home $(-4 \%)$.

Table 2: Past-week compliance with social distancing recommendations ( $\%$ following distancing rules, T1 and T2) $n=889$, weighted data.

\begin{tabular}{|c|c|c|c|}
\hline In the last seven days, have you done any the following? & $\mathrm{T} 1(\%)$ & $\mathrm{T} 2(\%)$ & $\begin{array}{l}\text { Change } \\
(\%)\end{array}$ \\
\hline $\begin{array}{l}\text { Gone out to a restaurant, bar, or other indoor place where people } \\
\text { gather }(\% \text { no) }\end{array}$ & 73.6 & 67.2 & -6.4 \\
\hline $\begin{array}{l}\text { Gone inside a friend, neighbor, or relative's residence that is not your } \\
\text { own }(\% \text { no) }\end{array}$ & 58.4 & 56.9 & -1.5 \\
\hline $\begin{array}{l}\text { Had visitors such as friends, neighbors or relatives inside your } \\
\text { residence }(\% \text { no) }\end{array}$ & 56.0 & 53.4 & -2.6 \\
\hline $\begin{array}{l}\text { Remained in your residence at all times, except for essential activities } \\
\text { or exercise (\% yes) }\end{array}$ & 59.2 & 55.2 & -4.0 \\
\hline $\begin{array}{l}\text { Had close contact-within about } 6 \text { feet-with people who do not live } \\
\text { with you (\% no) }\end{array}$ & 30.1 & 26.8 & -3.3 \\
\hline
\end{tabular}


Most of the eight false beliefs that made up the misinformation belief scale garnered substantial disagreement at T1 (more than 55\% disagreed with 6 of 8) (Table 3). Still, about $35 \%$ of the sample were unsure or agreed with at least half of the false beliefs; only $9 \%$ strongly disagreed with all eight. About $43 \%$ were not sure or agreed with the statement that public health authorities were exaggerating the seriousness of COVID-19, with $45 \%$ not sure or agreeing with the claim that "Information about treatments for coronavirus is being suppressed by those who want the pandemic to continue." These proportions stayed consistent over time, with less than a 5\% point change from $\mathrm{T} 1$ to $\mathrm{T} 2$ for each item. As will be shown below, the mean summed scale score did not change between waves. Table 4 presents univariate information and the bivariate associations of the five T1 scales with each other, with the T2 scales, and with the potential confounders.

Table 3: Misinformation beliefs ( $\%$ answering strongly disagree or disagree, T1 and T2) $n=$ 889 , weighted data.

\begin{tabular}{|c|c|c|c|}
\hline & $\mathrm{T} 1$ & $\mathrm{~T} 2$ & $\begin{array}{l}\text { Change } \\
(\%)\end{array}$ \\
\hline $\begin{array}{l}\text { How much do you (disagree) or (agree) with the following } \\
\text { statements: }\end{array}$ & \multicolumn{2}{|c|}{$\%$ disagree } & \\
\hline Coronavirus is probably a hoax & 81.3 & 83.7 & 2.4 \\
\hline $\begin{array}{l}\text { Public health authorities are exaggerating the seriousness of } \\
\text { coronavirus }\end{array}$ & 56.7 & 60.2 & 3.5 \\
\hline A vaccine for the coronavirus is now available & 67.3 & 66.5 & -.8 \\
\hline $\begin{array}{l}\text { The malaria drug Hydroxychloroquine is an effective } \\
\text { treatment for coronavirus }\end{array}$ & 49.7 & 44.9 & -4.8 \\
\hline A cure for coronavirus has been found & 64.3 & 65.5 & 1.2 \\
\hline $\begin{array}{l}\text { Information about treatments for coronavirus is being } \\
\text { suppressed by those who want the pandemic to continue }\end{array}$ & 55.0 & 55.5 & 0.5 \\
\hline Coronavirus was created in a lab & 33.0 & 35.2 & 2.2 \\
\hline The coronavirus is not more dangerous than the seasonal flu & 61.7 & 62.1 & 0.4 \\
\hline $\begin{array}{l}\text { If people wear masks it will slow the development of } \\
\text { widespread immunity to coronavirus* }\end{array}$ & 34.4 & -- & -- \\
\hline $\begin{array}{l}\text { if people social distance it will slow the development of } \\
\text { widespread immunity to coronavirus* }\end{array}$ & 25.2 & -- & -- \\
\hline
\end{tabular}




\section{Cross-Sectional Results}

We measured cross-sectional associations between belief in misinformation and protective behaviors, controlling for potential confounders, and then controlling for behavior-specific beliefs. At T1, face mask wearing was negatively correlated with belief in misinformation ( $\mathrm{r}$ $=-.21)$ but was much more associated with beliefs around face mask wearing $(r=.43)$.

Similarly, at T1, social distancing behavior was negatively correlated with belief in misinformation $(\mathrm{r}=-.21)$ but much more associated with beliefs around social distancing $(\mathrm{r}=$ .38). As previously noted, the two behavioral belief scales were highly inter-correlated $(\mathrm{r}=$ .90), likely reflecting their parallel question structure, but we did not use these scales concurrently in any multivariate analyses.

With a few exceptions, the potential confounders were not substantially correlated $(|\mathrm{r}|$ $<.20)$ with the focus scales. Belief in misinformation was less common among respondents with higher levels of education $(r=-.34)$ and among higher income respondents $(r=-.23)$; face mask wearing was more common among those who rented rather than owned their own homes $(r=.26)$. All of the remaining 72 correlations between the $\mathrm{T} 1$ scales and potential confounders were between -.20 and +.20 . 
Table 4: Univariate information and correlations of primary variables with each other and with potential confounders $(\mathrm{T} 1 \& \mathrm{~T} 2) n=889$, weighted data.

\begin{tabular}{|c|c|c|c|c|c|c|c|}
\hline & \multirow[b]{2}{*}{$\begin{array}{l}\text { Univariate } \\
\text { information } \\
\text { (M/sd) or \% }\end{array}$} & \multicolumn{5}{|c|}{ Time 1 Measures } \\
\hline & & & $\begin{array}{c}\text { Face } \\
\text { mask } \\
\text { wearing }\end{array}$ & $\begin{array}{c}\text { Pro-Face } \\
\text { mask } \\
\text { wearing } \\
\text { beliefs }\end{array}$ & $\begin{array}{c}\text { Social } \\
\text { Distancing }\end{array}$ & $\begin{array}{l}\text { Pro-social } \\
\text { distancing } \\
\text { beliefs }\end{array}$ & $\begin{array}{l}\text { Misinfo } \\
\text { scale }\end{array}$ \\
\hline \multirow{22}{*}{ 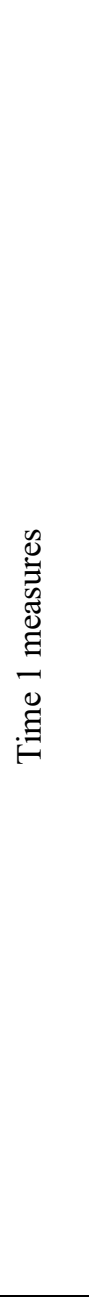 } & Face mask wearing (1-4) & $2.3(.92)$ & & & & & \\
\hline & $\begin{array}{l}\text { Pro-Face mask wearing } \\
\text { beliefs (1-4) }\end{array}$ & $3.2(.80)$ & .43 & & & & \\
\hline & Social Distancing (1-5) & $2.8(1.5)$ & .43 & .39 & & & \\
\hline & $\begin{array}{l}\text { Pro-social distancing beliefs } \\
(1-4)\end{array}$ & $3.3(.75)$ & .43 & .90 & .38 & & \\
\hline & Misinformation scale & $2.0(.65)$ & -.21 & -.51 & -.21 & -.50 & \\
\hline & Education in years $(1-20)$ & $14.1(2.8)$ & -.06 & .08 & -.01 & .09 & -.34 \\
\hline & Age (years) & $47.6(18)$ & .06 & .05 & .18 & .05 & -.11 \\
\hline & $\begin{array}{l}\text { Gender }(\mathrm{M}=1 ; \mathrm{F}=2 ; \\
\text { other=missing })\end{array}$ & $51 \% \mathrm{~F}$ & .14 & .10 & .10 & .11 & .06 \\
\hline & Income $(5 \mathrm{k}$ to $150 \mathrm{~K}+)$ & $68 \mathrm{k}(50)$ & -.12 & .01 & -.09 & .01 & -.21 \\
\hline & Black vs all others & $11 \%$ & .12 & .01 & .00 & .04 & .03 \\
\hline & White vs all others & $72 \%$ & -.17 & -.08 & -.03 & -.05 & .00 \\
\hline & Latinx/Hispanic vs all others & $16 \%$ & .19 & .11 & .03 & .09 & .03 \\
\hline & $\begin{array}{l}\text { Marital status (partner vs } \\
\text { not) }\end{array}$ & $63 \%$ & -.10 & -.05 & .05 & -.04 & .01 \\
\hline & HH size $(1-16)$ & $2.9(1.6)$ & -.04 & -.04 & -.05 & -.05 & .10 \\
\hline & Kids $<18$ or not. & $32 \%$ & -.07 & -.04 & -.07 & -.04 & .14 \\
\hline & $\begin{array}{l}\text { Employed or not (pre- } \\
\text { pandemic) }\end{array}$ & $56 \%$ & -.01 & -.06 & -.12 & -.09 & -.04 \\
\hline & Health insured or not & $90 \%$ & .03 & -.01 & -.06 & .00 & -.01 \\
\hline & Home owned vs. rented & $65 \%$ & .26 & .08 & .02 & .07 & .09 \\
\hline & Northeast & $18 \%$ & .14 & .08 & .01 & .06 & -.03 \\
\hline & Northcentral & $21 \%$ & -.16 & -.04 & -.04 & -.06 & -.05 \\
\hline & South & $37 \%$ & -.03 & -.01 & -.01 & .00 & .10 \\
\hline & West & $24 \%$ & .07 & -.03 & .03 & .00 & -.04 \\
\hline \multirow{5}{*}{ 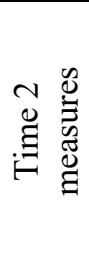 } & Face mask wearing & $2.6(.88)$ & .65 & .42 & .28 & .40 & -.19 \\
\hline & Pro-face mask beliefs & $3.4(.76)$ & .40 & .76 & .32 & .75 & -.55 \\
\hline & Social distancing & $2.6(1.6)$ & .34 & .32 & .56 & .34 & -.18 \\
\hline & Pro-social distancing beliefs & $3.4(.72)$ & .40 & .74 & .36 & .75 & -.52 \\
\hline & Misinformation scale & $2.0(.66)$ & -.21 & -.51 & -.21 & -.49 & .84 \\
\hline
\end{tabular}


Table 4 also shows the consistent negative relationships between belief in

misinformation and each of the protective behaviors at both waves of measurement $(r=-.21$

in every case). Table 5 elaborates this result with a series of cross-sectional multivariate

analyses (using all of the T1 cases). Models 1a and 2a show the simple bivariate

unstandardized associations between belief in misinformation and each of the behaviors;

models $1 \mathrm{~b}$ and $2 \mathrm{~b}$ show the misinformation coefficients for each behavior when the full set of

potential confounders are entered into the equations. Finally, models $1 \mathrm{c}$ and $2 \mathrm{c}$ show the

coefficients when the confounders, belief in misinformation, and the relevant behavioral

beliefs are included.

Table 5: Cross-sectional protective behaviors regressed on misinformation, confounders $^{1}$ and behavioral beliefs. Results of MPlus FIML linear regression models (unstandardized coefficients and standard errors)

\begin{tabular}{|c|c|c|c|c|c|c|}
\hline & \multicolumn{3}{|c|}{ Face mask wearing } & \multicolumn{3}{|c|}{ Social distancing } \\
\hline & $\begin{array}{l}\text { Model 1a: } \\
\text { simple }\end{array}$ & $\begin{array}{l}\text { Model 1b: } \\
\text { Adjusted for } \\
\text { confounders }\end{array}$ & $\begin{array}{l}\text { Model 1c: } \\
\text { Including } \\
\text { behavioral } \\
\text { beliefs and } \\
\text { confounders }\end{array}$ & $\begin{array}{l}\text { Model 2a: } \\
\text { simple }\end{array}$ & $\begin{array}{l}\text { Model 2b: } \\
\text { Adjusted for } \\
\text { confounders }\end{array}$ & $\begin{array}{l}\text { Model 2c: } \\
\text { Including } \\
\text { behavioral } \\
\text { beliefs and } \\
\text { confounders }\end{array}$ \\
\hline Misinformation & $-.27(.06)$ & $-.34(.05)$ & $-.06(.06)$ & $-.46(.08)$ & -.55 (.09) & $-.17(.10)$ \\
\hline $\begin{array}{l}\text { Face mask } \\
\text { behavioral beliefs }\end{array}$ & & & $.43(.05)$ & & & \\
\hline $\begin{array}{l}\text { Social distancing } \\
\text { behavioral beliefs }\end{array}$ & & & & & & $63(.09)$ \\
\hline R-square & .035 & .236 & .325 & .039 & .127 & .192 \\
\hline
\end{tabular}

Note. Bolded results $\mathrm{p}<.001$; effective weighted $n=1,074$ for all models; missing values (between 0-92 by equation) were handled using full information maximum likelihood method (FIML); parameters were estimated using maximum likelihood with robust standard errors (MLR) with sampling weights via MPlus 8.3. Confounders listed in Table 4. See Supplemental Table $\mathrm{S} 1$ for parameter estimates of confounders in models $1 \mathrm{~b}, 1 \mathrm{c}, 2 \mathrm{~b}$ and $2 \mathrm{c}$.

The cross-sectional association of belief in misinformation with both protective behaviors not only remains significant but increases in magnitude when the confounders are incorporated in the models. However, this pattern changes once the relevant behavioral beliefs are added to the equations. For face mask wearing, the association of belief in misinformation is effectively accounted for - the significant unstandardized coefficient found 
in Model 1b $(\mathrm{B}=-.33$, se $=.05)$ becomes small and not different from zero in Model $1 \mathrm{c}(\mathrm{B}=$ $-.05, \mathrm{se}=.06)$ while the coefficient for the newly entered face mask wearing beliefs variable is large $(\mathrm{B}=.43, \mathrm{se}=.05)$. The same pattern appears for social distance behaviors. The Model $2 \mathrm{~b}$ confounder-controlled coefficient $(\mathrm{B}=-.53, \mathrm{se}=.09)$ falls sharply in Model 2c $(\mathrm{B}$ $=-.15, \mathrm{se}=.10)$, and behavioral beliefs are strongly related to social distancing behavior $(\mathrm{B}=$ .62 , se $=.09$ ). The complete equations, including coefficients for the confounders, can be found in the online supplement.

\section{Longitudinal Results}

The cross-sectional analyses establish that the association between misinformation and behavior disappears once beliefs about the consequences of those behaviors are statistically controlled. However, the belief-behavior regressions - adjusted for confounders do not establish a causal order between the beliefs and behavior; it is possible that behavior actually leads to beliefs. The next longitudinal analyses ask whether the beliefs are not only associated with behaviors, but also predict them. Do beliefs at T1 predict behavior at T2 when adjusted for behavior at T1? Figure 1a (for face mask wearing) and Figure $1 \mathrm{~b}$ (for social distancing) present cross-lagged panel models, weighted and incorporating confounders. As shown in these figures, for both behaviors, T1 beliefs are substantial lagged predictors of $\mathrm{T} 2$ behavior $(\mathrm{B}=.20(.04)$ for mask wearing and $\mathrm{B}=.31(.08)$ for social distancing), over and above the substantial associations of $\mathrm{T} 1$ behavior and $\mathrm{T} 2$ behavior and the cross-sectional relationships of $\mathrm{T} 1$ belief and $\mathrm{T} 1$ behavior. In addition, there is evidence of a smaller but significant lagged reciprocal effect of $\mathrm{T} 1$ behavior on $\mathrm{T} 2$ beliefs for both behaviors. In contrast, and consistent with the cross-sectional results, belief in misinformation at $\mathrm{T} 1$ does not predict either $\mathrm{T} 2$ behavior when $\mathrm{T} 1$ behavior and $\mathrm{T} 1$ beliefs are controlled (face mask wearing partial correlation $=.00$; social distancing partial correlation $=.04$ ). 
Figure 1a: Face Mask Wearing Cross-Lagged Analysis Results. (MLR estimation results after controlling for confounders; missing values were handled using FIML; $n=889$ )

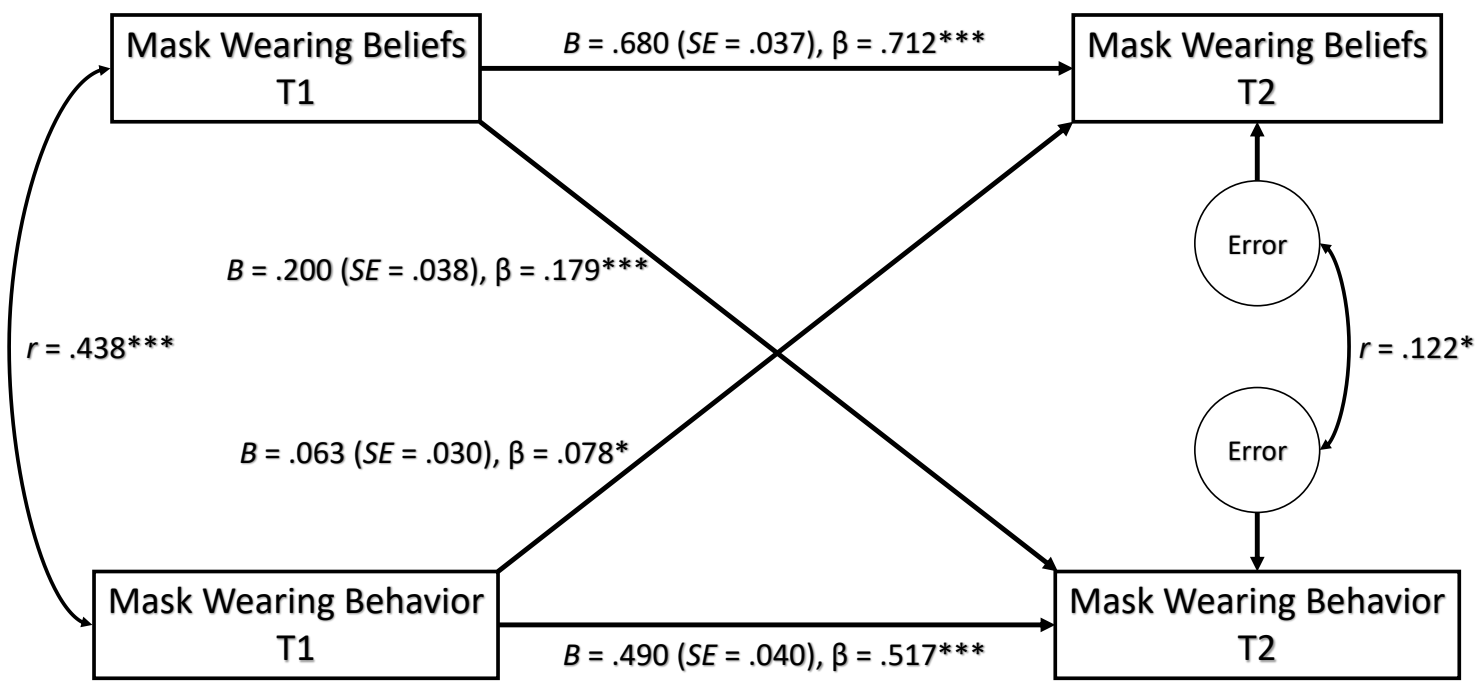

Figure 1b: Social Distancing Cross-Lagged Analysis Results. (MLR estimation results after controlling for confounders; missing values were handled using FIML; $n=889$ )

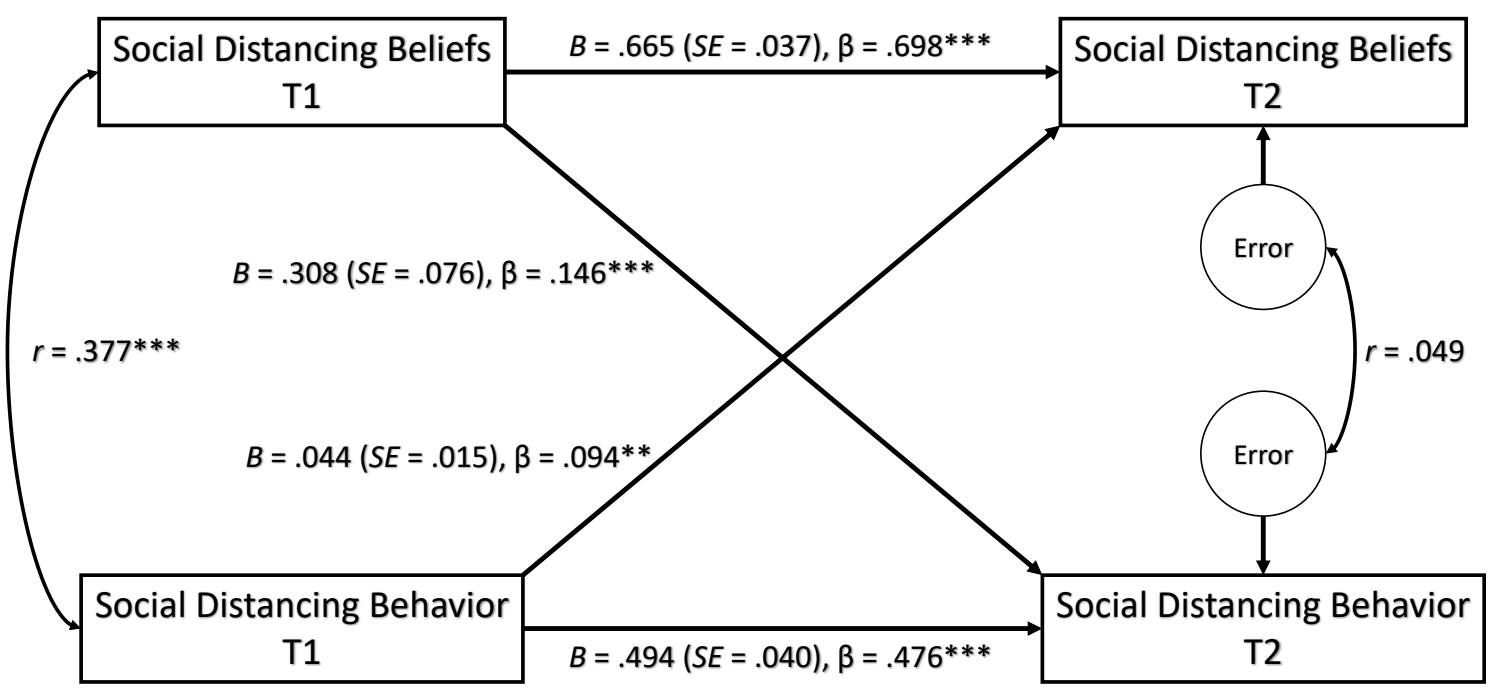




\section{Discussion}

Overall, there is substantial evidence for both the quality of and variation in our five core variables. These measures are all substantially associated with one another. Misinformation beliefs did not shift over time; face mask wearing increased and social distancing decreased slightly. We found the cross-sectional associations (at both $\mathrm{T} 1$ and $\mathrm{T} 2$ ) of both protective behaviors (face mask wearing and social distancing) with belief in misinformation are significant and negative, even after adjusting for potential confounders. However, the relationships between belief in misinformation and protective behaviors are smaller than the relationships between the protective behaviors and their related beliefs. Further, misinformation-protective behaviors associations disappear after adjusting for behavioral beliefs. In longitudinal analyses, we found that behavior-specific beliefs (and not belief in misinformation) were significant lagged predictors of protective behaviors, further supporting an inference that these beliefs are not only correlated with behavior but also predict change in those behaviors.

We pre-registered a hypothesis related to the original $\mathrm{T} 1$ cross-sectional study that the association of misinformation beliefs with protective behaviors would be minimized in comparison with behavior-specific beliefs (https://aspredicted.org/blind.php? $\mathrm{x}=\mathrm{g} 2 \mathrm{eq} 8 \mathrm{w}$ ); the results both do and do not conform to the pre-registered hypothesis. The misinformation measure is substantially associated with both of the protective behaviors even when we adjust for a wide range of potential confounders, consistent with some prior studies. On the other hand, as predicted, belief in misinformation is less associated with those behaviors than the behavioral beliefs directly tied to those behaviors, and the association between belief in misinformation and protective behaviors largely disappears when the analysis adjusts for behavioral beliefs, both cross-sectionally and in the lagged analyses. We recognize that there are multiple interpretations consistent with those results. 
Interpretation 1: Beliefs about consequences lead to adoption of protective behaviors (although there is reciprocal influence as well). The particular beliefs measured may be specifically influential or may be indicators of a set of beliefs that underpin a strong positive attitude towards the behaviors.

Interpretation 2: It may also be that misinformation does influence behavior, but its influence is entirely mediated through the behavioral beliefs (consistent with the reasoned action approach).

Interpretation 3: On the other hand, misinformation may have no substantive role in influencing behavior, even indirectly. The association of beliefs about behavioral consequences and misinformation might be a reflection of influences (in opposite directions) by common external forces. However, only beliefs about consequences affect adoption of protective behaviors.

All three of these interpretations are consistent with regard to their conclusion about a potential path to influencing protective behaviors: engaging with behavioral beliefs rather than misinformation. A final interpretation recognizes a limitation of the research design, and while not challenging the disregard of misinformation, is less confident about the promise of a campaign focused on behavioral beliefs.

Interpretation 4: Some unmeasured confounders, such as skepticism around public health concerns, affect all measured variables (belief in misinformation, behavioral beliefs, and protective behaviors) and account for the observed cross-sectional and lagged associations of the beliefs and behavior. For this interpretation to be true, those unmeasured confounders would need to be independent of the measured confounders, which were shown not to reduce the effects of beliefs. Also, they would have to have time varying effects; to explain the lagged effects of beliefs measured at $\mathrm{T} 1$ on behavior measured at $\mathrm{T} 2$, 
unmeasured confounders would need to have both effects on belief at T1 and effects on behavior at $\mathrm{T} 2$ that were not accounted for by their effects on behavior at $\mathrm{T} 1$.

This study has clear strengths. To our knowledge it is the first to engage with and compare the effects of misinformation in the context of behavioral beliefs on COVID-19related protected behaviors. There is good evidence for the validity of the focus measures. The large sample is drawn from an established nationally representative panel. The two rounds of data collection six weeks apart permitted replication of the results with both crosssectional and longitudinal analyses. The potential weaknesses are shared with any surveybased observational study: reliance on self-reported behaviors, concerns about unmeasured confounders not completely dealt with by the longitudinal design, and possible biases of the sampling procedures producing an analytic sample imperfectly representing the population.

\section{Implications for Health Communication}

Causal claims from observational data, even longitudinal observational data, are necessarily uncertain. Nonetheless, these results do bear on thinking about what beliefs ought to be the target of public communication campaigns. Specifically, they suggest that a communication intervention directly addressing misinformation beliefs is likely to be less promising than one directly addressing the specific behavioral beliefs around the protective behaviors. The results suggest that despite the moderate association of belief in misinformation with behavior, directly targeting such false beliefs may be unnecessary for encouraging protective behaviors.

Addressing such beliefs is unnecessary in the context of health campaigns because any influence they might have on behaviors is accounted for by the direct behavioral beliefs. Focusing on addressing specific behavioral beliefs may also be preferable given the difficulty of effectively correcting misinformation. While some strategies have been found to be 
effective at correcting misinformation, the effectiveness of different types of correctives varies greatly (Meer \& Jin, 2020; Walter \& Murphy, 2018), and misinformation about infectious diseases may be particularly difficult to correct (Walter et al., 2020). Moreover, even after correction, misinformation can continue to have negative effects on people's attitudes due to the persistence of a "belief echo" (Thorson, 2016). Further complicating matters, coronavirus-related misinformation has included hundreds if not thousands of discrete rumors (as can be seen from perusing fact-checking websites such as snopes.com), which have emerged across a number of different media platforms and have waxed and waned in their prominence over the course of the pandemic. Thus, identifying which pieces of misinformation need to be corrected and the ideal platforms through which to issue corrective communications would be a great challenge.

In contrast, both theory (i.e. Fishbein \& Ajzen, 2015) and the evidence presented here speak to the promise of prioritizing direct behavioral beliefs, regardless of false beliefs. Each of the specific beliefs is a candidate for persuasive interventions. Campaigns would focus on moving people from disagreement or less than strong agreement with these beliefs which are highly associated with behaviors (you will protect more vulnerable people in our society; you will help the healthcare system so that people who need urgent medical care will receive it; you will slow the spread of the coronavirus; it will prevent you from transmitting coronavirus to others; your family and friends will approve of your decision; you will be less likely to get sick). While this study cannot establish that a campaign which successfully addressed these beliefs would also influence adoption of behaviors, it does create the beginning of a roadmap for priority focus for such campaigns (Brennan et al., 2017; Hornik et al., 2019). 
Table S1: Protective behaviors predicted by misinformation, confounders, and behavioral beliefs. (Results of MPlus FIML linear regression models (unstandardized coefficients and standard errors)?

\begin{tabular}{|c|c|c|c|c|c|c|}
\hline & \multicolumn{3}{|c|}{ Face mask wearing } & \multicolumn{3}{|c|}{ Social distancing } \\
\hline & $\begin{array}{l}\text { Model } \\
\text { 1a: } \\
\text { simple }\end{array}$ & $\begin{array}{l}\text { Model 1b: } \\
\text { Adjusted for } \\
\text { confounders }\end{array}$ & $\begin{array}{c}\text { Model } 1 \mathrm{c}: \\
\text { Including } \\
\text { behavioral } \\
\text { beliefs }+ \\
\text { confounders }\end{array}$ & $\begin{array}{l}\text { Model } \\
\text { 2a: } \\
\text { simple }\end{array}$ & $\begin{array}{l}\text { Model 2b: } \\
\text { Adjusted for } \\
\text { confounders }\end{array}$ & $\begin{array}{c}\text { Model } 2 \mathrm{c} \text { : } \\
\text { Including } \\
\text { behavioral } \\
\text { beliefs }+ \\
\text { confounders }\end{array}$ \\
\hline Misinformation & $\begin{array}{c}-.27 \\
(.06)^{* * *}\end{array}$ & $-.34(.05)^{* * *}$ & $-.06(.06)$ & $\begin{array}{c}-.46 \\
(.08)^{* * *}\end{array}$ & $-.55(.09)^{* * *}$ & $-.17(.10)$ \\
\hline $\begin{array}{l}\text { Face mask } \\
\text { behavioral beliefs }\end{array}$ & & & $.43(.05)^{* * *}$ & & & \\
\hline $\begin{array}{l}\text { Social distancing } \\
\text { behavioral beliefs }\end{array}$ & & & & & & $.63(.09)^{* * *}$ \\
\hline $\begin{array}{l}\text { Education in } \\
\text { years }(1-20)\end{array}$ & & $-.02(.02)$ & $-.015(.014)$ & & $-.004(.023)$ & $.01(.02)$ \\
\hline Age (years) & & $.007(.002)^{* *}$ & $.007(.002)^{* *}$ & & $\begin{array}{c}.013 \\
(.004)^{* * *}\end{array}$ & $\begin{array}{c}.013 \\
(.004)^{* * *}\end{array}$ \\
\hline $\begin{array}{l}\text { Gender }(\mathrm{M}=1 \text {; } \\
\mathrm{F}=2 \text {; other } \\
\text { missing })\end{array}$ & & $.18(.07)^{* *}$ & $.115(.061)$ & & $.24(.12)^{*}$ & $.14(.11)$ \\
\hline $\begin{array}{l}\text { Income ( } 5 \mathrm{k} \text { to } \\
150 \mathrm{~K}+)\end{array}$ & & $-.002(.001)$ & $-.002(.001)$ & & $\begin{array}{c}-.004 \\
(.001)^{* *}\end{array}$ & $\begin{array}{c}-.004 \\
(.001)^{* *}\end{array}$ \\
\hline $\begin{array}{l}\text { Black vs all } \\
\text { others }\end{array}$ & & $.26(.14)$ & $.24(.13)$ & & $.20(.22)$ & $.13(.21)$ \\
\hline $\begin{array}{l}\text { White vs all } \\
\text { others }\end{array}$ & & $-.26(.10)^{* *}$ & $-.22(.09)^{*}$ & & $-.24(.16)$ & $-.21(.16)$ \\
\hline $\begin{array}{l}\text { Latinx/Hispanic } \\
\text { vs all others }\end{array}$ & & $.43(.10)^{* * *}$ & $.30(.10)^{* *}$ & & $.24(.18)$ & $.11(.18)$ \\
\hline $\begin{array}{l}\text { Marital status } \\
\text { (partner vs not) }\end{array}$ & & $-.02(.08)$ & $-.03(.07)$ & & $.40(.14)^{* *}$ & $.38(.13)^{* *}$ \\
\hline HH size (1-16) & & $-.01(.03)$ & $-.01(.02)$ & & $.01(.05)$ & $.02(.05)$ \\
\hline Kids $<18$ or not. & & $-.15(.09)$ & $-.15(.08)$ & & $-.07(.16)$ & $-.06(.16)$ \\
\hline $\begin{array}{l}\text { Employed or not } \\
\text { (pre-pandemic) }\end{array}$ & & $.08(.08)$ & $.13(.07)$ & & $-.22(.14)$ & $-.12(.13)$ \\
\hline $\begin{array}{l}\text { Health insured or } \\
\text { not }\end{array}$ & & $.08(.11)$ & $.10(.11)$ & & $-.26(.17)$ & $-.25(.16)$ \\
\hline $\begin{array}{l}\text { Home owned or } \\
\text { rented }\end{array}$ & & $.37(.08)^{* * *}$ & $.31(.08)^{* * *}$ & & $.16(.14)$ & $.08(.14)$ \\
\hline Northeast & & $.22(.10)^{*}$ & $.13(.09)$ & & $.004(.178)$ & $-.07(.17)$ \\
\hline Northcentral & & $-.26(.10)^{* *}$ & $-.28(.09)^{* * *}$ & & $-.13(.18)$ & $-.11(.16)$ \\
\hline South & & $-.16(.09)$ & $-.20(.09)^{*}$ & & $.06(.15)$ & $-.09(.15)$ \\
\hline $\mathrm{R}$-square & .035 & .236 & .325 & .039 & .127 & .192 \\
\hline
\end{tabular}

Note. $*, \mathrm{p}<.05 ; * *, \mathrm{p}<.01 ; * * *, \mathrm{p}<.001$; effective weighted $n=1,074$ for all models; missing values (between 0-92 by variable) were handled using full information maximum likelihood method (FIML); parameters were estimated using maximum likelihood with robust standard errors (MLR) with sampling weights via MPlus 8.3. 
Acknowledgements: We are grateful to Jazmyne Sutton and Eran Ben Porath of SSRS and Laura Gibson, Andy Tan, Rui Pei and Emily Falk at the University of Pennsylvania for their contributions to the development of the survey instrument.

Author contributions: RH led and worked on all aspects of the study; LS, KK also did data analysis; all co-authors contributed to the development of the study design, drafting of the questionnaire, as well as writing and reviewing drafts. Authors after RH are listed in random order since all contributed equally. 


\section{References}

Allington, D., Duffy, B., Wessely, S., Dhavan, N., \& Rubin, J. (2020). Health-protective behaviour, social media usage and conspiracy belief during the COVID-19 public health emergency. Psychological Medicine, 1-7. https://doi.org/10.1017/S003329172000224X

Alper, S., Bayrak, F., \& Yilmaz, O. (2020). Psychological correlates of COVID-19 conspiracy beliefs and preventive measures: Evidence from Turkey. Current Psychology (New Brunswick, N.j.), 1-10. https://doi.org/10.1007/s12144-020-00903-0

Banai, I., Banai, B., \& Mikloušić, I. (2020). Beliefs in COVID-19 conspiracy theories predict lower level of compliance with the preventive measures both directly and indirectly by lowering trust in government medical officials [Preprint]. PsyArXiv. https://doi.org/10.31234/osf.io/yevq7

Bertin, P., Nera, K., \& Delouvée, S. (2020). Conspiracy beliefs, chloroquine, and the rejection of vaccination: A conceptual replication-extension in the COVID-19 pandemic context [Preprint]. PsyArXiv. https://psyarxiv.com/rz78k/

Bierwiaczonek, K., Kunst, J. R., \& Pich, O. (2020). Belief in COVID-19 conspiracy theories reduces social distancing over time [Preprint]. PsyArXiv. https://doi.org/10.31234/osf.io/tqfrw

Bogart, L. M., Wagner, G., Galvan, F. H., \& Banks, D. (2010). Conspiracy beliefs about HIV are related to antiretroviral treatment nonadherence among african american men with HIV. Journal of Acquired Immune Deficiency Syndromes (1999), 53(5), 648-655. https://doi.org/10.1097/QAI.0b013e3181c57dbc

Brennan, E., Gibson, L. A., Kybert-Momjian, A., Liu, J., \& Hornik, R. C. (2017). Promising themes for antismoking campaigns targeting youth and young adults. Tobacco Regulatory Science, 3(1), 29-46. https://doi.org/10.18001/TRS.3.1.4

Brennen, J. S., Simon, F. M., Howard, P. N., \& Nielsen, R. K. (2020). Types, sources, and claims of COVID-19 misinformation. Reuters Institute for the Study of Journalism, 13. 
Centers for Disease Control. (2020, February 11). Prevent getting sick. Centers for Disease Control and Prevention. https://www.cdc.gov/coronavirus/2019-ncov/prevent-getting-sick/socialdistancing.html

Cook, J., Ecker, U., \& Lewandowsky, S. (2015). Misinformation and how to correct it. In Emerging Trends in the Social and Behavioral Sciences (pp. 1-17). American Cancer Society. https://doi.org/10.1002/9781118900772.etrds0222

Depoux, A., Martin, S., Karafillakis, E., Preet, R., Wilder-Smith, A., \& Larson, H. (2020). The pandemic of social media panic travels faster than the COVID-19 outbreak. Journal of Travel Medicine, 27(3). https://doi.org/10.1093/jtm/taaa031

Díaz, R., \& Cova, F. (2020). Moral values and trait pathogen disgust predict compliance with official recommendations regarding COVID-19 pandemic in US samples [Preprint]. PsyArXiv. https://doi.org/10.31234/osf.io/5zrqx

Erceg, N., Ružojčić, M., \& Galic, Z. (2020). Misbehaving in the corona crisis: The role of anxiety and unfounded beliefs [Preprint]. PsyArXiv. https://doi.org/10.31234/osf.io/cgjw8

Fishbein, M., \& Ajzen, I. (2015). Predicting and changing behavior (1 edition). Routledge.

Fishbein, M., Triandis, H., Kanfer, F. H., Becker, M., Middlestadt, S. E., \& Eichler, A. (2001).

Factors influencing behavior and behaviour change. In Handbook of Health Psychology (pp. 3-17). Lawrence Erlbaum.

Guess, A., Nyhan, B., \& Reifler, J. (2018). Selective exposure to misinformation: Evidence from the consumption of fake news during the 2016 U.S. presidential campaign. European Research Council, 9. http://www.ask-force.org/web/Fundamentalists/Guess-Selective-Exposure-toMisinformation-Evidence-Presidential-Campaign-2018.pdf

Hornik, R. C., Volinsky, A. C., Mannis, S., Gibson, L. A., Brennan, E., Lee, S. J., \& Tan, A. S. L. (2019). Validating the Hornik \& Woolf approach to choosing media campaign themes: Do promising beliefs predict behavior change in a longitudinal study? Communication Methods and Measures, 13(1), 60-68. https://doi.org/10.1080/19312458.2018.1515902

IFCN Covid-19 Misinformation. (n.d.). Poynter. Retrieved May 15, 2020, from https://www.poynter.org/ifcn-covid-19-misinformation/ 
Imhoff, R., \& Lamberty, P. (2020). A bioweapon or a hoax? The link between distinct conspiracy beliefs about the coronavirus disease (COVID-19) outbreak and pandemic behavior. Social Psychological and Personality Science. https://doi.org/10.1177/1948550620934692

Jolley, D., \& Douglas, K. M. (2014). The effects of anti-vaccine conspiracy theories on vaccination intentions. PLOS ONE, 9(2), e89177. https://doi.org/10.1371/journal.pone.0089177

Kouzy, R., Abi Jaoude, J., Kraitem, A., El Alam, M. B., Karam, B., Adib, E., Zarka, J., Traboulsi, C., Akl, E. W., \& Baddour, K. (2020). Coronavirus goes viral: Quantifying the COVID-19 misinformation epidemic on Twitter. Cureus, 12(3), e7255. https://doi.org/10.7759/cureus.7255

Kreps, S. E., \& Kriner, D. (2020). Medical misinformation in the COVID-19 pandemic (SSRN Scholarly Paper ID 3624510). Social Science Research Network. https://doi.org/10.2139/ssrn.3624510

Meer, T. G. L. A. van der, \& Jin, Y. (2020). Seeking formula for misinformation treatment in public health crises: The effects of corrective information type and source. Health Communication, 35(5), 560-575. https://doi.org/10.1080/10410236.2019.1573295

Mian, A., \& Khan, S. (2020). Coronavirus: The spread of misinformation. BMC Medicine, 18(1), 89. https://doi.org/10.1186/s12916-020-01556-3

Misinformation related to the COVID-19 pandemic. (2020). In Wikipedia. https://en.wikipedia.org/w/index.php?title=Misinformation_related_to_the_COVID19 pandemic\&oldid $=965215105$

Nan, X., Wang, Y., \& Thier, K. (in press). Health misinformation. In Thompson, T \& Harrington, N (Eds.), The Routledge Handbook of Health Communication. https://doi.org/10.31234/osf.io/6mrgv

Oliver, J. E., \& Wood, T. (2014). Medical conspiracy theories and health behaviors in the United States. JAMA Internal Medicine, 174(5), 817-818. https://doi.org/10.1001/jamainternmed.2014.190 
Pennycook, G., McPhetres, J., Bago, B., \& Rand, D. (2020). Attitudes about COVID-19 in Canada, the U.K., and the U.S.A.: A novel test of political polarization and motivated reasoning [Preprint]. PsyArXiv. https://psyarxiv.com/zhjkp/

Pummerer, L., \& Sassenberg, K. (2020). Conspiracy theories in times of crisis and their societal effects: Case “corona” [Preprint]. PsyArXiv. https://psyarxiv.com/y5grn/

Sharma, K., Seo, S., Meng, C., Rambhatla, S., \& Liu, Y. (2020). COVID-19 on social media: Analyzing misinformation in Twitter conversations. http://arxiv.org/abs/2003.12309

Social Science Research Solutions (SSRS). (n.d.). Retrieved June 27, 2020, from https://ssrs.com/opinion-panel/

Southwell, B. G., Niederdeppe, J., Cappella, J. N., Gaysynsky, A., Kelley, D. E., Oh, A., Peterson, E. B., \& Chou, W.-Y. S. (2019). Misinformation as a misunderstood challenge to public health. American Journal of Preventive Medicine, 57(2), 282-285. https://doi.org/10.1016/j.amepre.2019.03.009

Sternisko, A., Cichocka, A., Cislak, A., \& Van Bavel, J. J. (2020). Collective narcissism predicts the belief and dissemination of conspiracy theories during the COVID-19 pandemic [Preprint]. PsyArXiv. https://doi.org/10.31234/osf.io/4c6av

Swami, V., \& Barron, D. (2020). Analytic thinking, rejection of coronavirus (COVID-19) conspiracy theories, and compliance with mandated social-distancing: Direct and indirect relationships in a nationally representative sample of adults in the United Kingdom [Preprint]. OSF Preprints. https://osf.io/nmx9w/

Teovanovic, P., Lukic, P., Zupan, Z., Lazić, A., Ninković, M., \& Zezelj, I. (2020). Irrational beliefs differentially predict adherence to guidelines and pseudoscientific practices during the COVID-19 pandemic [Preprint]. PsyArXiv. https://doi.org/10.31234/osf.io/gefhn

Thorburn, S., \& Bogart, L. M. (2005). Conspiracy beliefs about birth control: Barriers to pregnancy prevention among African Americans of reproductive age. Health Education \& Behavior: The Official Publication of the Society for Public Health Education, 32(4), 474-487. https://doi.org/10.1177/1090198105276220 
Thorson, E. (2016). Belief echoes: The persistent effects of corrected misinformation. Political Communication, 33(3), 460-480. https://doi.org/10.1080/10584609.2015.1102187

Walter, N., Brooks, J. J., Saucier, C. J., \& Suresh, S. (2020). Evaluating the impact of attempts to correct health misinformation on social media: A meta-analysis. Health Communication, $0(0)$, 1-9. https://doi.org/10.1080/10410236.2020.1794553

Walter, N., \& Murphy, S. T. (2018). How to unring the bell: A meta-analytic approach to correction of misinformation. Communication Monographs, 85(3), 423-441. https://doi.org/10.1080/03637751.2018.1467564

WHO Myth busters. (n.d.). Retrieved May 15, 2020, from https://www.who.int/emergencies/diseases/novel-coronavirus-2019/advice-for-public/mythbusters 